\title{
A Researchon Treatment of Type II Diabetes using Combinational Herbal Compounds
}

\author{
R.Priya, E.Sugitha, Vasundra
}

\begin{abstract}
Diabetes is the common disorder found in case of metabolic disfunction leads to high blood glucose level in our body. Type two polygenic diseases are that the most typical type of polygenic disease. If we have type 2 diabetes our body does not use insulin properly. This is called insulin resistance. At first, our pancreas makes extra insulin to make up for it. But, over time it's not able to carry on and cannot create enough internal secretion to stay your blood sugar at traditional levels. In order to cure Type II diabetes we have identified the gene responsible for the insulin resistance gene from the genomic information resource database. The gene is further analysed and docked with the four herbal components and checked its minimum energy value for further studies. This will be the combination drug and using Nano medicine which will be the target drug delivery towards the target gene which stimulates the activity of the insulin resistant gene. Since its targets towards the gene it will be considered as the gene therapy and new combinatorial medicine, here Bioinformatics, combinatorial chemistry, pharmacology, Nano medicine play a vital role in treatment of diabetes.

Type II diabetes is the high risk of day to day life, so considering these facts the gene responsible for diabetes is identified and diagnosis of DNA is done used molecular techniques and mutated gene is identified for further treatment.

In this project suitable drug targets is identified and targeted towards the type II diabetes.
\end{abstract}

Keywords: Type 2 Diabetes, Insulin Secretions, Target drug delivery.

\section{INTRODUCTION}

People with kind two polygenic disorders will still build endocrine, however their cells have some extent of endocrine resistance. Long-term complications from high glucose embody cardiovascular disease, strokes, diabetic retinopathy which might lead to anceity, renal disorder, and poor blood flow within the limbs which can lead to amputations.

\section{The Root Causes of Type II Diabetes:}

According to the medical news the researcher says Type 2 diabetes to be an immune problem whereby the immune system attacks the body's own cells. Type 2 diabetes is being reclassified as an immune system malady as opposed to only a metabolic issue, said a creator of another

Revised Manuscript Received on August 19, 2019.

DR. R.Priya,Associate Professor, Department of Genetic Engineering, BIHER, Chennai.T.N, India(priya.microbio@gmail.com)

E.Sugitha,BTECH Genetic Engg.Department of Genetic Engineering. BIHER, Chennai, T.N, India

Vasundra,BTECH Genetic Engg. Department of Genetic Engineering, BIHER, Chennai, T.N, India examination distributed in Nature medicine in the week, the discoveries of which may prompt new diabetes medications that objective the safe framework as opposed to attempting to control glucose.

The researchers believe that hypoglycemic agent resistance, the hallmark of type 2 diabetes (unlike type 1 diabetes where it is the insulin-producing cells that are destroyed), is the result of B cells and other immune cells attacking the body's own tissues.

This discovery is nothing unaccustomed some natural medication researchers. Treatments that do the items necessary to make the system are hardening sort a pair of polygenic disease for years. The symptoms of diabetes are polyuria, polydipsia, and polyphagia and weight loss. Many folks, however, have no symptoms during the first few years and are diagnosed on routine testing. People with sort a pair of diabetes could seldom gift with hyperosmolar hyperglycaemic state.

\section{MATERIALS AND METHODS:}

1. Identification of the target gene in type II diabetes.IRS 1

Gene This gene encodes a protein which is phosphorylated by insulin receptor tyrosine kinase. Mutations in this gene are associated with type II diabetes and susceptibility to insulin resistance. [provided by RefSeq, Nov 2009]-NCBI.

2. Selection of herbal drug compounds.

The Four herbal ligands were selected using PUBCHEM database in which the compound which is responsible for reducing the blood glucose are identified by the literature survey and studied the mechanism of action for each compound were taken for drug designing. The selected herbal compounds are Curcuma longa, Syzgiumcumini, Gymnemasylvestre, Trigonellafoenumgraecum

3. Study of gene and its analysis.

Gene analysis is done using GENEVIEWER tool which results in Gene location and the sequence id and number of sequence present in the target gene.

\section{Drug designing.}

Drug Designing is done using CHEMSKETCH tool to draw and join the four compounds.

5. Molecular docking.

Molecular docking analysis is done using AUTODOCK 4.0 


\section{RESULTS AND DISCUSSION:}

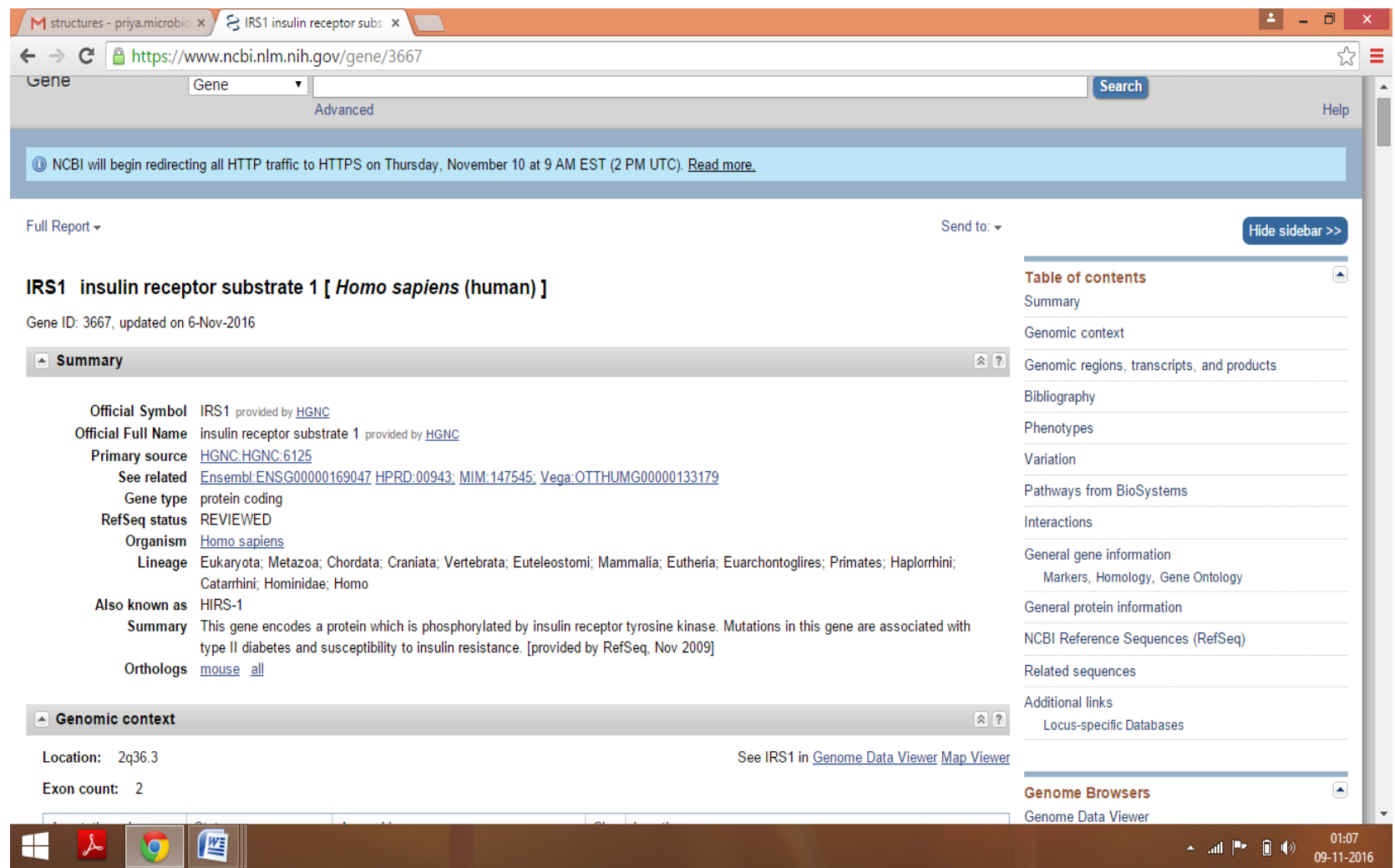

Fig:1 Target gene IRS1 is found using NCBI database.

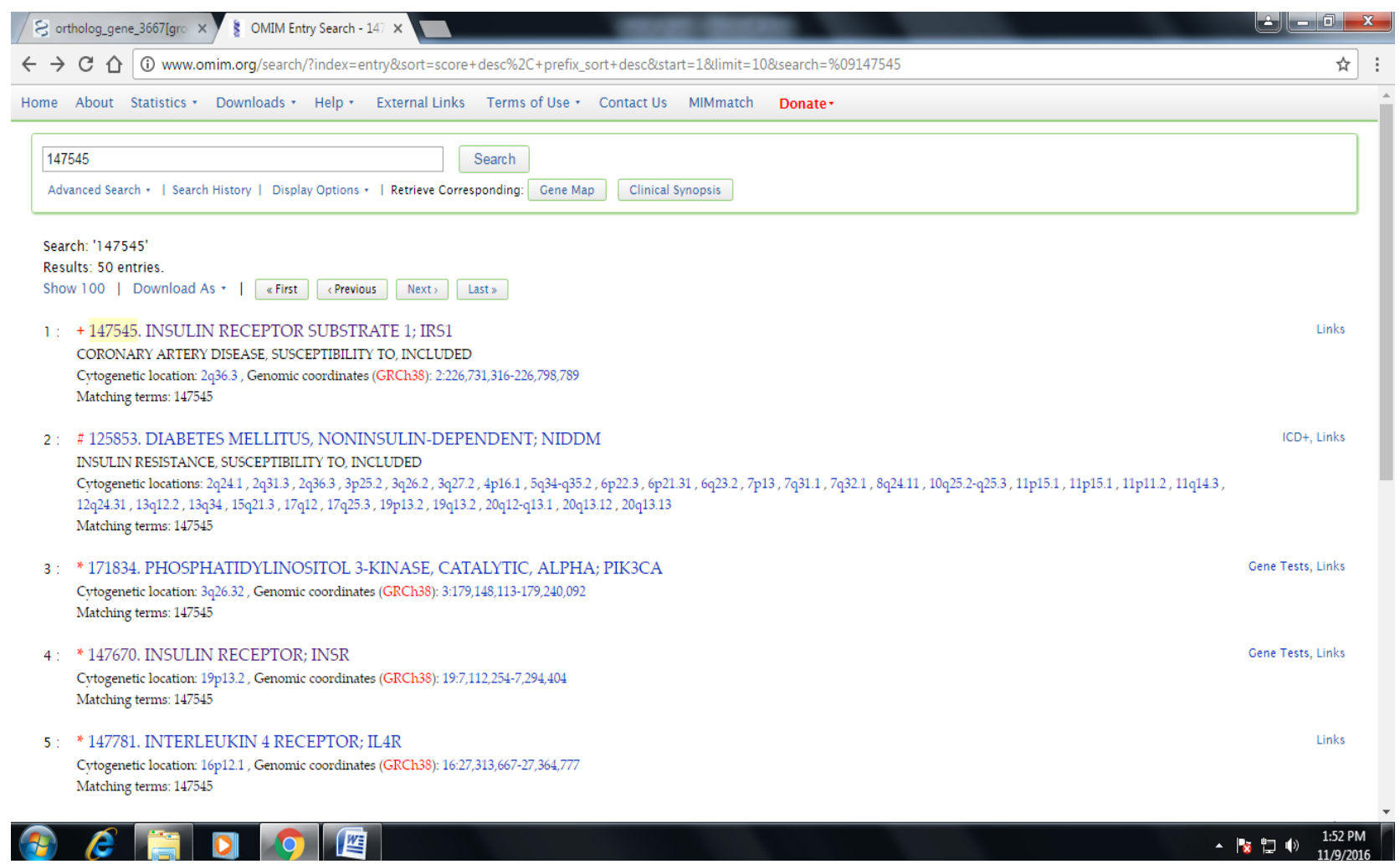

FIG:2 OMIM entry of the target gene . 


\section{HERBAL COMPOUNDS:}

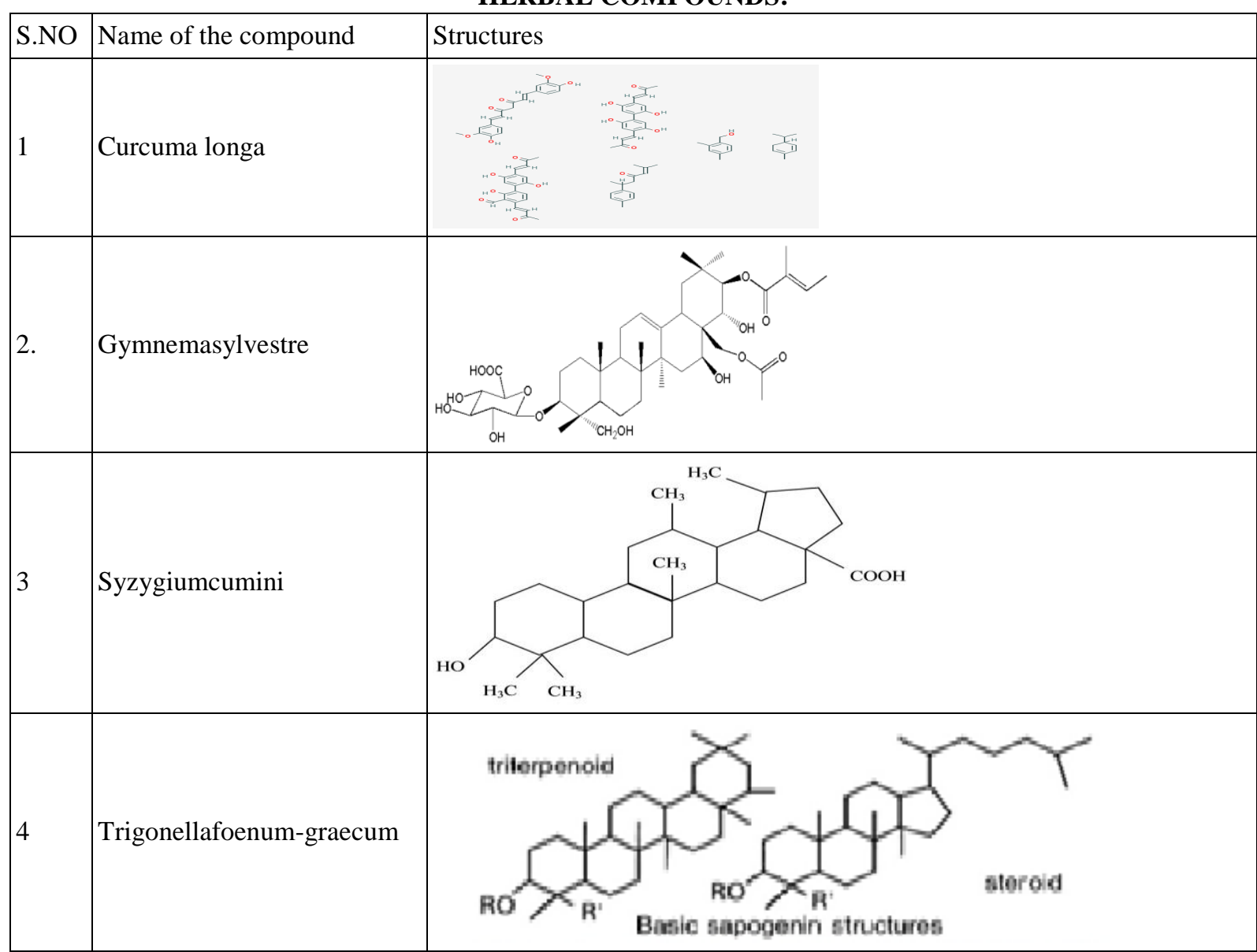

Fig 3: Ligand of the four herbal plants.

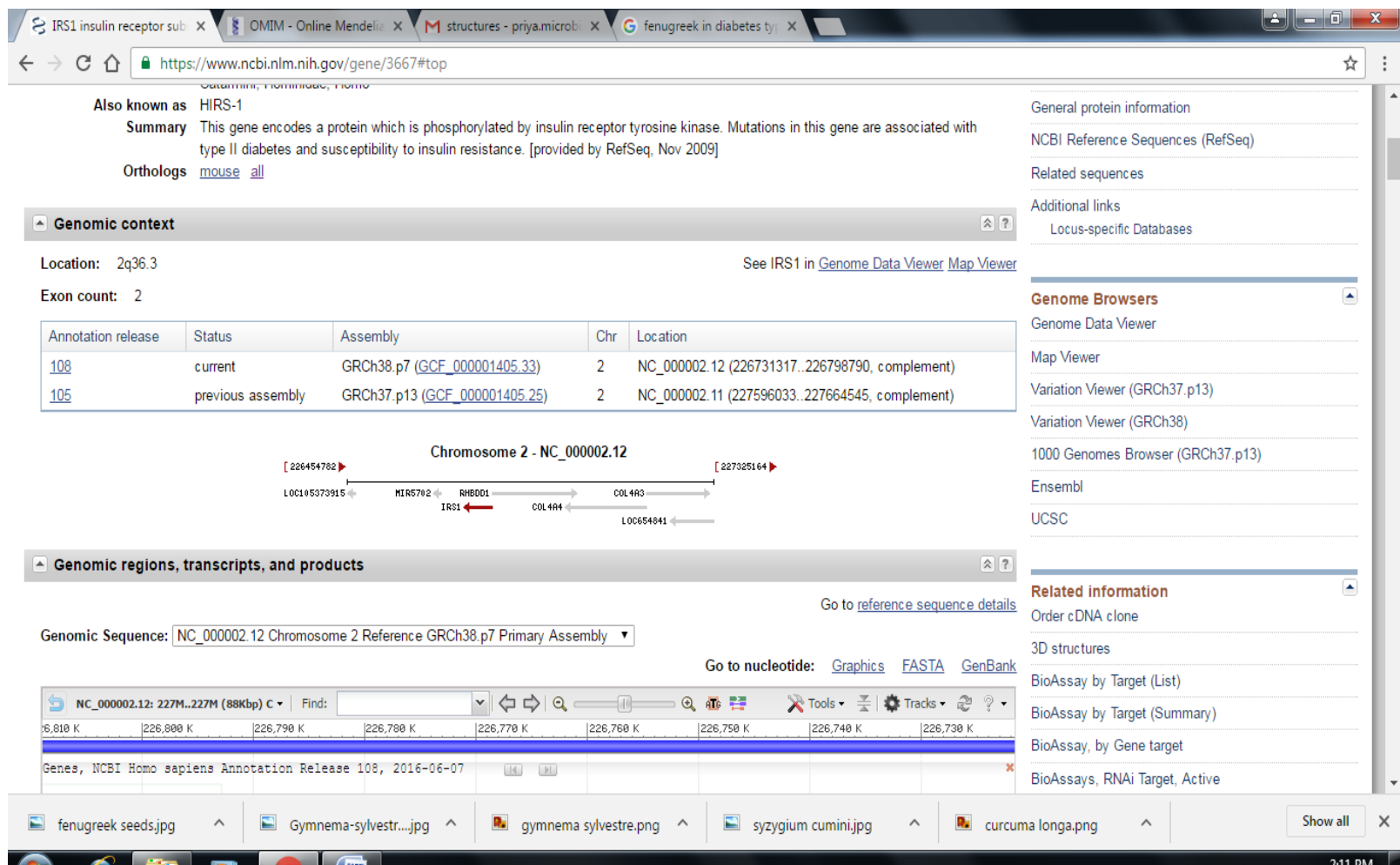

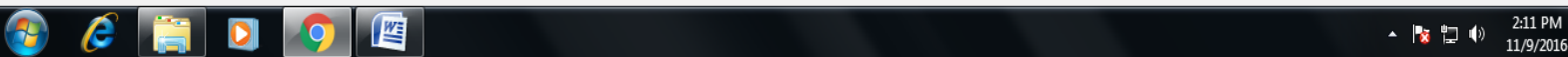

Fig: 4 gene location identification.

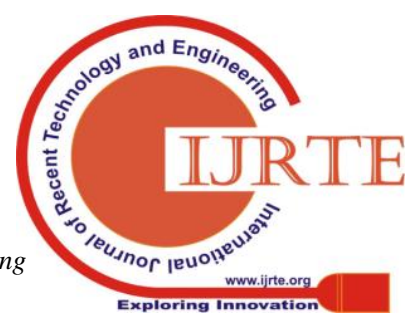




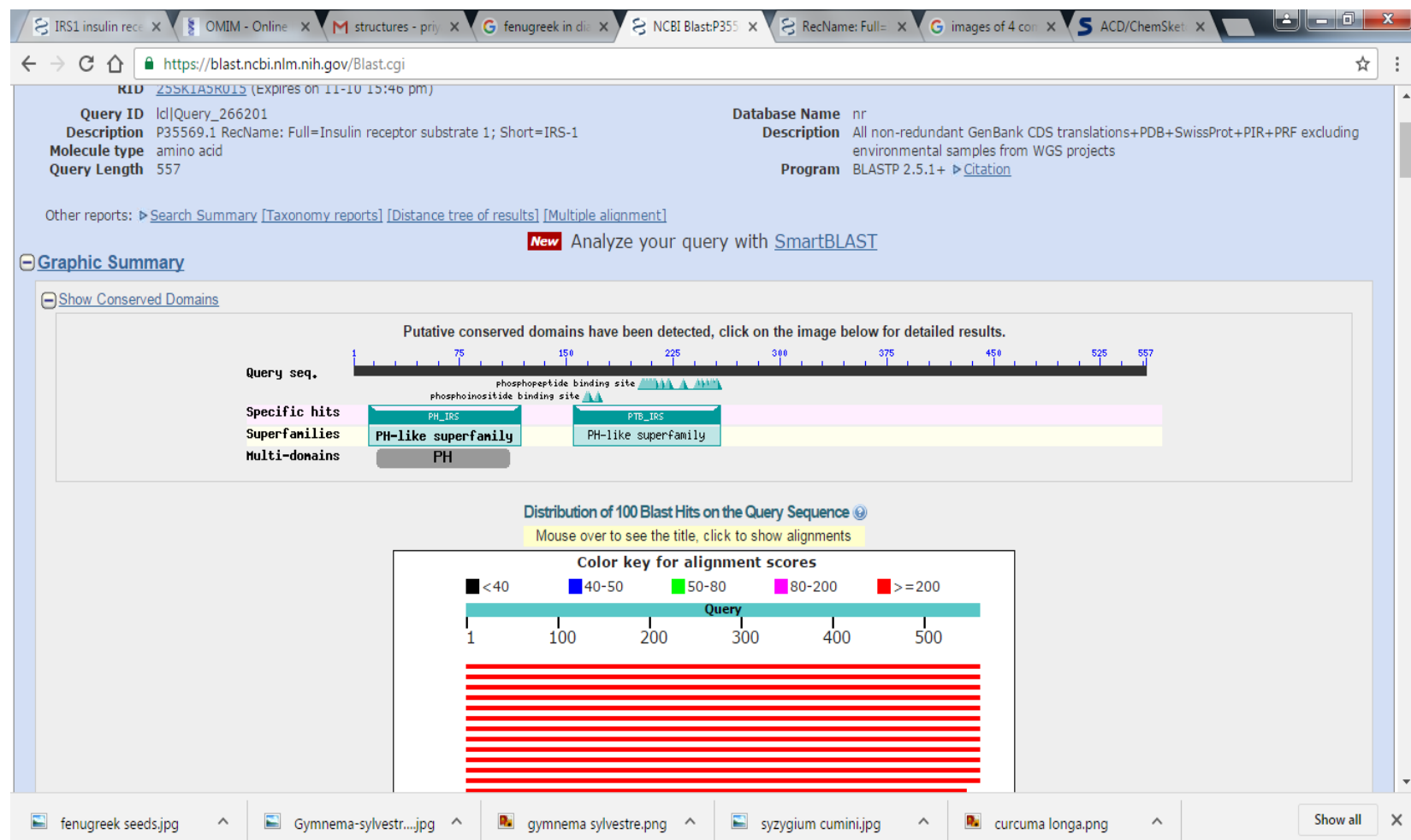

(4) E Fig 5: BLAST $p$ result indicates the most similarity search for the target gene.

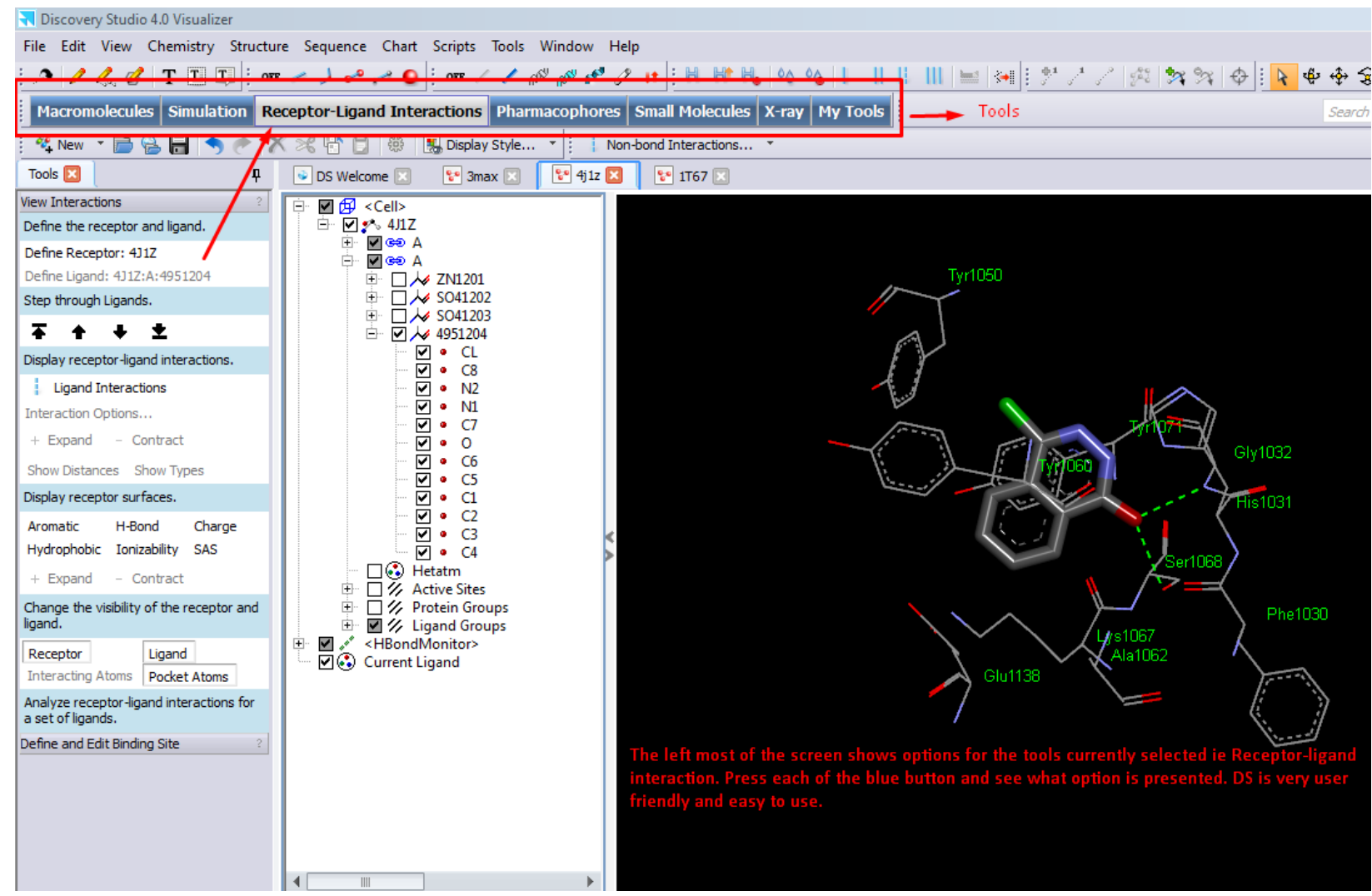

FIG 6: MOLECULAR DOCKING using AUTO DOCK software. 


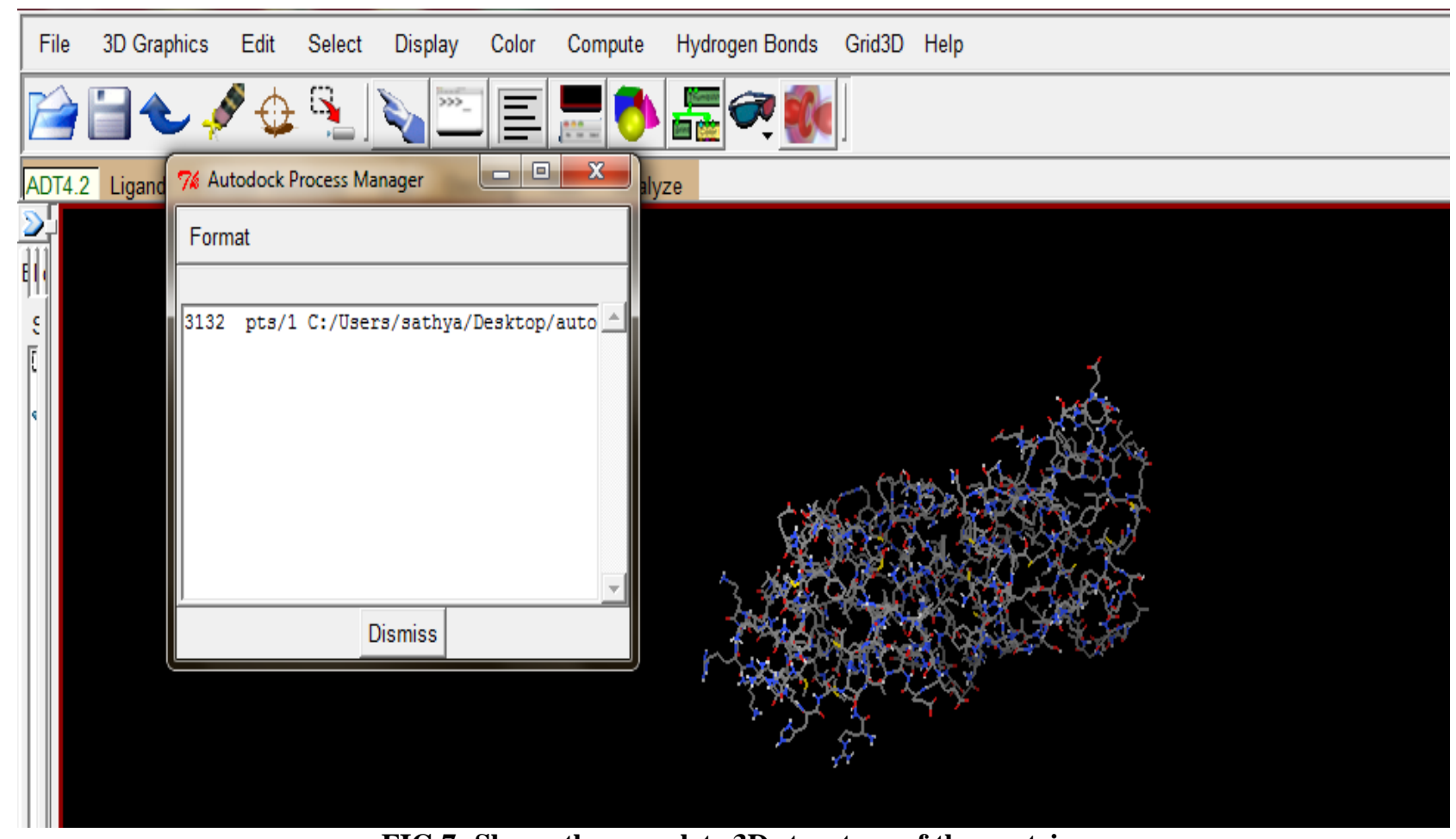

FIG 7: Shows the complete 3D structure of the protein.

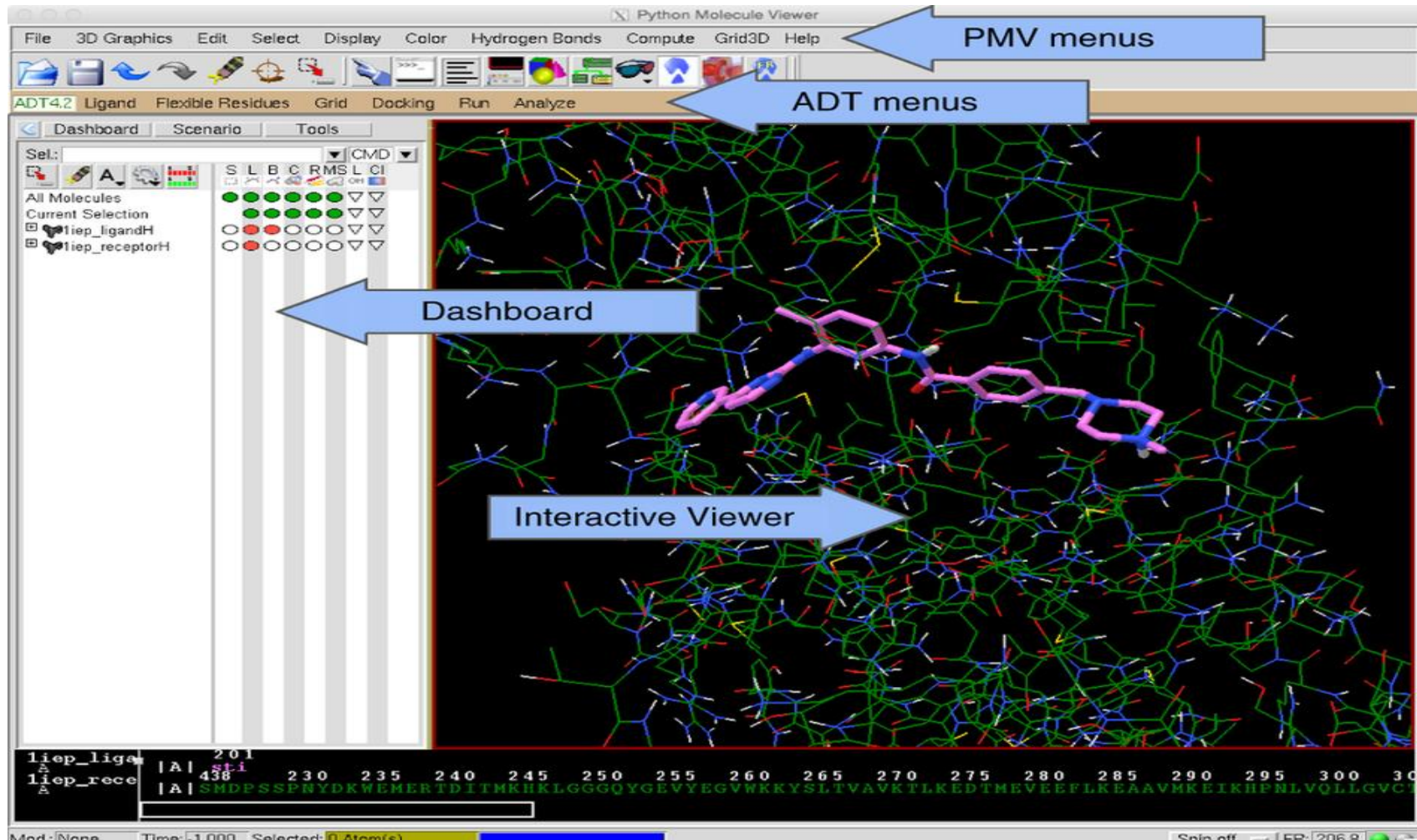

Fig: 8 Docked ligand pinkcolour indicates the designed Drug and the green colour indicates the structure of the protein(IRS 1 gene)

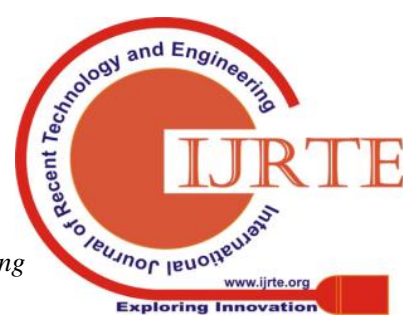




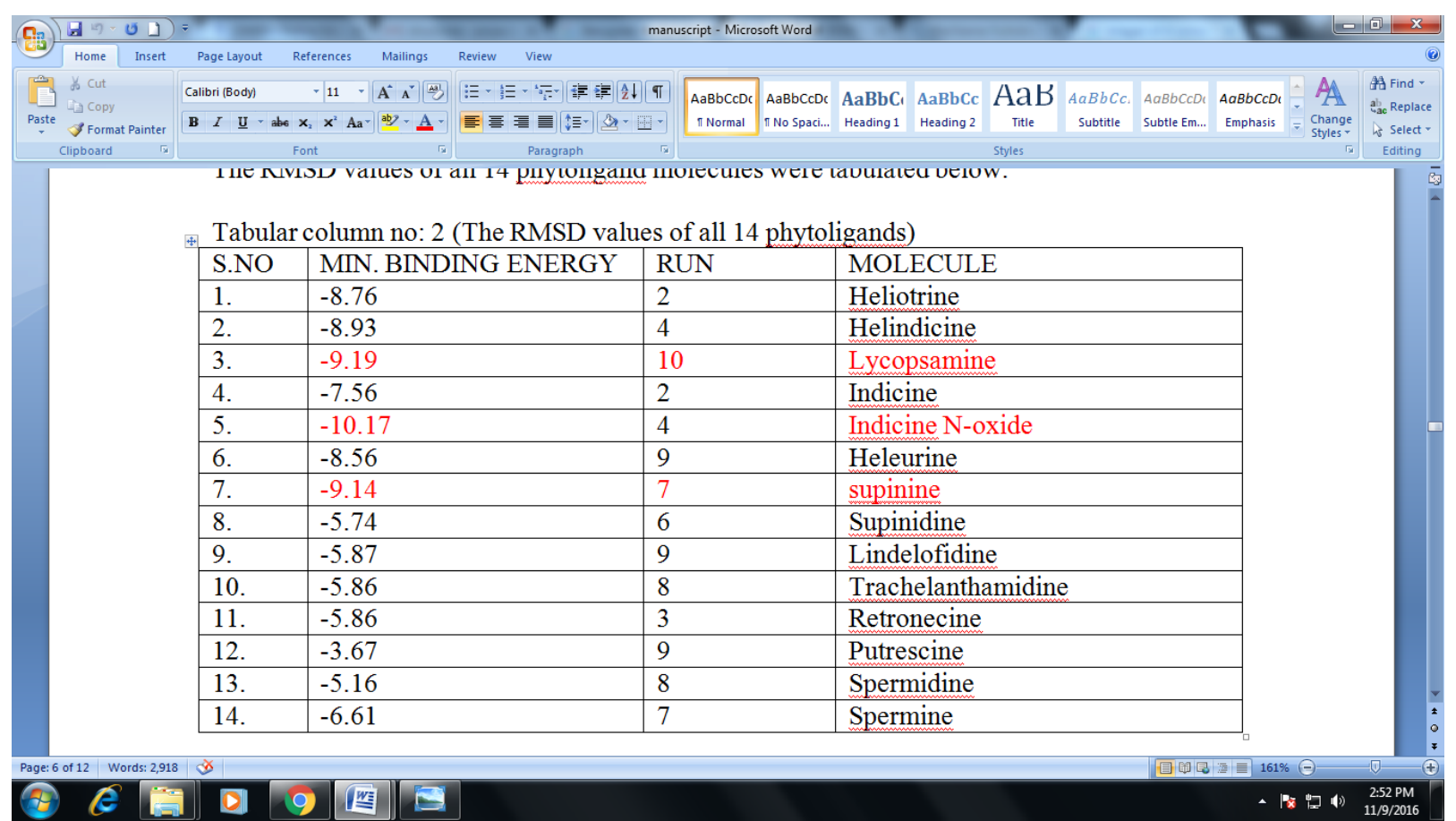

Fig 9: Minimum energy values are listed for the compounds the minimum energy value is showed for the best binding energy between the new drug compound and the diabetes protein, the red colour highlighted compounds shows the best binding energy value for the target gene.

\section{CONCLUSION}

In order to cure Type II diabetes we have identified the gene responsible for the insulin resistance gene from the genomic information resource database. The gene is further analysed and docked with the four herbal components and checked its minimum energy value for further studies. This will be the combination drug and using Nano medicine which will be the target drug delivery towards the target gene which stimulates the activity of the insulin resistant gene. Since its targets towards the gene it will be considered as the gene therapy and new combinatorial medicine, here Bioinformatics, combinatorial chemistry, pharmacology, Nano medicine play a vital role in treatment of diabetes.

\section{REFERENCES:}

1. Treatment of colorectal cancer using Nanotechnology.R.Priya, Dr.R.Vasugi, IJPT| Sep-2015 | Vol.7 | Issue No.2 | 8977-898.

2. Green synthesis of Silver Nano particle by Semecarpusanacardium, plumbagozeylanica and curcuma longa Extracts and characterization of silver Nanoparticle. K.Senthilkumar, Dr.R.Vasuki, R.Priya, Jul- Aug, 2016, RJPBCS/7(4) Page no.502.

3. Green synthesis PEGlyation of silver NanoHerbal complex and study of its antimutagenicity

4. Activity. K.Senthilkumar, Dr.R.Vasuki, R.Priya, IJPT /jun2016/vol.8/Issue No.12/12130/12143.

5. Finding the High specific target gene among cry1Ac \& cry $2 \mathrm{Ab}$ in resistance to Pesticide. R.Priya, Rashmi Das, Dr.P.B.Rameshbabu, July-Aug, 2016, RJPBCS, 7(4), page No. 3070.

6. Molecular Mechanics, Drug Designing and Docking studies on mutated Gene CASP9 - Caspase 9, apoptosis - related cysteine peptidase) in Colorectal cancer in Human using Cheminformatics software and tools. R.Priya, DR. R. Vasuki and Senthilkumar.K, IJNTPS, vol 4/Number 4/AUG/2014. 